composed of the same traces, while differing with regard to the component traces' magnitudes. If we accept the proposition that the difference between two trace compounds is the sum total of the differences between the component traces' magnitudes, then it follows that a stimulus trigram (1-2-3) has greater similarity and therefore generalizes more with the two trigrams having the relative sequences 1-3-2 and 2-1.3 than with the rest, which have the relative sequences 3-2-1, 3-1-2, and 2-3-1.

The concept of trace compound and the notion that when two trace compounds have identical components, generalization between them is an inverse function of the aggregate magnitude difference between the identical component traces, have been utilized to interpret verbal learning phenomena in at least one other instance. Hull et al (1940) have offered an explanation of the forward and backward intralist errors in serial anticipation learning in terms of generalization between the trace compounds formed by the perseverative stimulus traces left by the syllables at preceding positions in the series. However, the validity of trace compound as an analytical device and of its use in the interpretation of stimulus generalization would essentially depend upon confirming evidences from the studies of conditioned response. To the writer's knowledge, the literature on conditioning does not offer any data by which this can be checked upon.

\section{REFERENCES}

DEY, M. K. An explanation of distributed practice efficacy in paired-associate learning. Journal of General Psychology, 1966, 74 61-75.

\title{
Bizarre images in artificial memory
}

GARY G. BRIGGS and STEPHEN HAWKINS, Duke University, Durham, N.C. 27706, and HERBERT F. CROVTTZ, Veterans Administration Hospital Durham, N.C. 27705

Recent work on the ancient art of artificial memory, in which first a set of places is memorized and then things or words are "put in those places with bizarre images," has shown that $S$ need not first commit a set of places to memory, but instead may successfully use a set of locations arbitrarily selected and provided by $E$. In the present study arbitrary "memory loci" and "bizarre images" are
FELDMAN, S. M., \& UNDERWOOD, B. J. $S$ timulus recall following paired-associate learning. Journal of Experimental Psychology, $1957,53,11-15$.

GIBSON, E. J. Intralist generalization as a factor in verbal learning. Journal of Experimental. Psychology, 1942, 32, 185-200.

HULL, C. L. Mind, mechanism and adaptive behavior. Psychological Review, 1937, 44, 1.32 .

HULL, C. L. Principles of behavior. New York: Appleton-Century-Crofts, 1943.

HULI, C. L. $A$ behavior system. New Haven: Yale University Press, 1952.

HULL, C. L., HOVLAND, C. I., ROSS, R. T. HALL, M., PERKINS, D. T., \& FITCH, F. B. Mathematico-deductive theory of rote learning. New Haven: Yale University Press, 1940. Facilitation in paired associate learning by distributed practice. Journal of Verbal Learning \& Verbal Behavior, 1962, 1, 258-263.

PLOTKIN, L. P. Stimulus generalization in Morse code learning. Archives of Psychology, 1943. 40 , No. 287.

UNDERWOOD, B. J. Studies of distributed practice: II. Learning and retention of paired-adjective lists with two levels of intralist similarity. Journal of Experimental Psychology, 1951, 42, 153-161.

UNDERWOOD, B. J. Studies of distributed practice: Vill. Learning and retention of paired nonsense syllables. Joumal of Experimental Psychology, 1953a, 45, 133-142.

UNDERWOOD, B. J. Studies of distributed practice: IX. Learning and retention of paired adjectives as a function of intra-list similarity. Journal of Experimental Psychology, 1953b, 45, 143-149.

UNDERWOOD, B. J., \& EKSTRAND, B. R. Effects of distributed practice on paired-associate learning. Journal of Experimental Psychology Monograph Supplement, 1967, 73(4, Whole No. 634).

\section{NOTE}

1. All requests for reprints should be mailed to P.o. Box 36, McMaster University, Hamilton, Ont., Canada
MARSHALL, M. A., \& RUNQUIST, W. N

with them. Crovitz (1969) has shown that Ss can use a set of arbitrary locations in the place of self-produced memory loci and can use them in forming "bizarre images" as mediators in one-trial paired-associate learning. Delin (1968) reported that the degree of "bizarreness" of mediating "images" is positively correlated with retention in PA learning, and Bugelski, Kidd, \& Segmen (1968) have reported that the time that is available for the "construction of the image" is a critical variable determining the effectiveness of the mnemonic technique.

The value of any mnemonic technique that facilitates retention and recall must depend upon the time and effort required for the successful use of the technique. The self-production of memory loci is not essential, as has been indicated; the present study was designed to determine whether self-production of "bizarre images" is itself essential.

A set of 20 fictitious locations along an artificial "map of Gorky Street" was drawn on a classroom blackboard, the 20 successively numbered locations corresponding to those used by Crovitz (1969). A set of 20 common, picturable English nouns had been randomly selected from the vocabulary of The System of Basic English (Ogden, 1934) and, prior to the experimental session, the authors, who are experienced in the classical art of artificial memory, fashioned sentences corresponding to "bizarre" mediators between the locations and the English nouns.

The Ss were 50 undergraduates, who participated as a course requirement, tested in a group. They were instructed: "This is an experiment involving the use of an artificial memory device. I will read you a list of words and give you an association between each word and the corresponding location on the blackboard. After I finish, write on your paper the list of words you were given, pairing them with the appropriate location. For example, BATHTUB: Imagine a whale in a bathtub. The word is WHALE. You would write the word WHALE at the number corresponding to the location BATHTUB. Now number your sheet from 1 to 20 .

1. ELECTRIC COMPANY. Picture a plow cutting an underground cable. The word is PLOW. (88\%)

2. GAS STATION. Picture the attendant angrily driving a nail into your tire. The word is NAIL. (94\%)

3. OCCULIST. Picture making the As described by Yates (1966), the ancient art of artificial memory required the storage in memory of a sequence of occulist mad, causing him to stick his locations and then the formation of finger in your eye. The word is FINGER. "bizarre images" as mediators between the (92\%) locations and the items to be associated 
Persian rug with a raffle ticket. The word is TICKET. (80\%)

5. FLORIST. Picture a florist in a flower-print shirt. The word is SHIRT. (84\%)

6. LOANS. Picture pawning the Brooklyn Bridge. The word is BRIDGE. $(56 \%)$

7. BUS TERMINAI. Picture a knife fight in the bus teıminal. The word is KNIFE. (92\%)

8. PLUMBER. Picture a plumber trying to loosen a stuck valve by tickling it with a feather. The word is FEATHER. (98\%)

9. JAIL. Picture getting out of jail and demanding a receipt as you leave. The word is RECEIPT. (88\%)

10. NEWSPAPER STAND. Picture the newspaper vendor taking a swig from his bottle hidden underneath the counter. The word is BOTTLE. ( $88 \%)$

11. SIDEWALK CAFE. Picture walking up to a sidewalk cafe and discovering a screen door with a huge lock. The word is LOCK. (90\%)

12. USED CARS. Picture a used car salesman trying to sponge you for every penny you own. The word is SPONGE. (92\%)

13. NURSERY. Picture the nursery children playing the game "ring around the rosey." The word is RING. (92\%)

14. DRY CLEANER. Picture the dry cleaner beating clothes with a stick. The word is STICK. (74\%)

15. GUNS. Picture throwing guns from a gun shop into an oven to melt them. The word is OVEN. (82\%)

16. PHONE BOOTH. Picture wanting to make a call in the phone booth and finding it boarded shut. The word is BOARD. (92\%)

17. DAIRY. Picture a garden inside the dairy. The word is GARDEN. (90\%)

18. PET STORE. Picture buying a kangaroo with boxing gloves. The word is BOX. (90\%)

19. MOTEL. Picture Conrad Hilton opening a Hilton Hotel on the first colonized star. The word is STAR. (92\%)

20. BOOK SHOP. Picture a tongue being used as a bookmark. The word is TONGUE. (78\%)"

The instructions and the list were read aloud by $E$ with no pauses between successive sentences, and immediately following the completion of the reading of the list, Ss attempted to write on their papers the list of words in the order given.

RESULTS AND DISCUSSION

The mean number of words written correctly in the 20-item list was 17.32 . Of the $50 \mathrm{Ss}, 17$ made perfect scores. Six Ss were correct on 19 items, 6 on 18,8 on 17 , 2 on 16,4 on 15,2 on 14 , and 1 on 13,12 , 11,10 , and 2 , respectively.
After each sentence listed above, the percentage of the $50 \mathrm{Ss}$ giving the correct noun in its proper location in the list is given in parentheses. Thus it can be seen that the most accurate recall was for 8. PLUMBER-FEATHER, while the least accurate recall was for 6. LOANS-BRIDGE.

The generally high level of performance indicates that self-produced "bizarre images" are not a necessary part of the mnemonic process and that the process operates in much the same way for most of the members of the population tested. Thus, it may be possible to make fairly extensive use of the artificial memory in the preparation of text materials where the form of the material to be learned by the student can be considered as long lists of paired associates. The advantages of textbooks that would give very high retention from a single reading are obvious. However, the possible serious disadvantages of a dependence upon the artificial memory process are suggested by the case study of Luria (1968). Luria's mnemonist was apparently expert in techniques including "placing bizarre images at stable locations" but missed abstract relations among items to be remembered, much like Ss in studies of the artificial memory who capitalize on concrete picturable attributes of the test material.

A major question raised by this study concerns the features of a mediator that leads to successful recall. Paivio (1969) has reviewed the evidence that points to the concreteness or image-evoking features of the items used in studies of associative learning. This study directly intervened in the associative process by supplying sentences that supplied a mediator between the items. The mediators were chosen to meet the traditional requirement for bizarre images in artificial memory: that is, if the event described by the bizarre image were to be seen, it would indeed be attention-provoking, a requirement which Yates (1966) attributes to the unknown author of the Ad Herennium of the first century B.C. Luria's mnemonist reported that he failed to remember items in a list when he had placed them in such a manner that he could not "see" them. For example, an EGG was omitted when he "placed" it against a white wall, where it faded into the background. Luria reported that errors made by the mnemonist were nearly always omissions rather than recall of incorrect items. This was also the case in the present study in which Ss presumably had no special practice in or aptitude for the artificial memory. The items most frequently missed may share a common characteristic. Items 4, 6, 14, and 20 may have been poor since the object to be remembered is either not the most visually arresting object in the mediation sentence or else it is difficult to "place" the objects in the specified relationship. For instance, it may be difficult to imagine physically putting the Brooklyn Bridge in the loan office. Further study of the mediators in paired-associate learning may clarify the features of them that make them vary with regard to their usefulness.

The present study grew out of the consideration of time in paired-associate learning. Bugelski, Kidd, \& Segmen (1968) reported data that indicates a minimum of about $4 \mathrm{sec}$ is required for PA learning when Ss construct their own mediators. The willingness of memory to use arbitrary memory loci and mediators supplied by $\mathrm{E}$ between the loci and the items to be associated with them may allow reduction of the time needed in PA learning, if it is quicker to use a mediator than to both form and use one.

Paivio \& Csabo (1969) reported a study in which a short list was presented at a very fast rate (about 5 items per second). In PA learning even rather short lists of under 10 items require several seconds per item for high performance one-trial learning. If all the time needed in PA learning with bizarre mediators is taken in forming mediators, the present finding that $S s$ can use mediators supplied by $\mathrm{E}$ may imply that, when mediation is supplied, the rate of PA learning is limited only by the rate at which mediation is delivered. In view of the relatively slow rate at which mediators were supplied (about $5 \mathrm{sec}$ per item), the present study is unable to answer this question. Since exploration of the time course of PA learning may be assisted by the present method of supplied mediation, it may be possible to design studies which will approach the discovery of the minimum time of associative learning.

\section{REFERENCES}

BUGELSKI, B. R., KIDD, E., \& SEGMEN, J. Image as a mediator in one-trial paired-associate learning. Journal of Experimental Psychology, 1968, 76, 69-73.

CROVITZ, H. F. Memory loci in artificial memory. Psychonomic Science, 1969, 16, 82-83.

DELIN, P. S. Success in recall as a function of success in implementation of mnemonic instructions. Psychonomic Science, 1968, 12 , 153-154.

LURIA, A. R. The mind of a mnemonist. New York: Basic Books, 1968.

OGDEN, C. K. The system of Basic English. New York: Harcourt, Brace, 1934.

PAIVIO, A. Mental imagery in associative learning and memory. Psychological Review, $1969,76,241-263$

PAIVIO, A., \& CSABO, K. Concrete image and verbal memory codes. Journal of Experimental Psychology, 1969, 80, 279-285.

YATES, F. A. The art of memory. Chicago: University of Chicago Press, 1966. 